\title{
Consonancias léxicas andinas en el lenguaje ritual mapuche williche: relaciones translingüísticas y estratificación histórica ${ }^{1}$
}

\section{Andean Lexical Consonances in the Mapuche Williche Ritual Language: Cross-linguistic Relationships and Historical Stratification}

\author{
RODRIGO MOULIAN \\ MARÍA CATRILEO \\ JAQUELINE CANIGUAN \\ FELIPE HASLER
}

Universidad Austral de Chile, Instituto de Comunicación Social. Chile. Correo electrónico: rmoulian@hotmail.com

Universidad Austral de Chile, Instituto de Lingüística y Literatura.

Correo electrónico: mcatrile@uach.cl

\begin{abstract}
Universidad de La Frontera, Departamento de Lenguas, Literatura y Comunicación.
Correo electrónico: jacqueline.caniguan@lafrontera.cl

Universidad de Chile, Departamento de Lingüística.

Correo electrónico: keche@gmail.com
\end{abstract}

El presente artículo identifica relaciones translingüísticas andinas en el lenguaje ritual mapuche williche y analiza contextualmente los vínculos interculturales que éstas implican. El repertorio de voces estudiadas incluye seis afines quechuas, siete registrados tanto en el quechua como en el aymara, un aymarismo, un puquinismo y una voz posiblemente derivada del puquina. En este corpus se distinguen dos estratos traslingüísticos andinos. El más extenso, compuesto por catorce voces cuya incorporación al mapudungun resulta atribuible al desarrollo del Tawantinsuyo, durante su expansión meridional en el siglo XV. El más reducido, numéricamente, pero más relevante en términos cualitativos, lo componen dos voces que revelan relaciones interculturales anteriores al incario, las que forman parte del lenguaje básico de la cultura mapuche y carecen de sinónimos en el

\footnotetext{
1 Este artículo presenta resultados del proyecto Fondecyt 1160388, Translingüística, supralingüística e interculturalidad: un estudio de casos de correlaciones en constelaciones semióticas centro y sur andinas indicadoras de cotradición.
} 
mapudungun. El análisis de las constelaciones semióticas de estos términos, es decir, de las series de interpretantes que especifican los significados y representaciones culturales de los mismos, muestra un sustrato ideológico preincaico compartido en el espacio centro y sur andino.

Palabras clave: translingüística, mapudungun, lenguaje ritual, lenguas andinas

This paper analyses some of the Andean cross-linguistic relationships in the Mapuche Williche ritual language and the intercultural link implied in them. The corpus includes six Quechua terms, seven terms coming from Quechua and Aymara, one Aymarized word, one Puquinisized term and one word possibly coming from Puquina, an older language spoken before Quechua. This corpus is divided into two Andean cross-linguistic strata. The most extensive one is composed of fourteen words probably incorporated into the Mapuche language (Mapudungun) during the development of the Tawantinsuyo in the 15th century. The less extensive one, from the point of view of the number of terms, is composed of only two items which are quite relevant because they reveal intercultural relationships that occurred before the Inka culture in the place. These embedded terms are part of the basic lexicon of the Mapuche language and culture and they lack synonyms in Mapudungun. The analysis of the semiotic constellations of these terms, i.e. the series of understandings implied in the specific sense and cultural meanings, display a pre Inka ideological substratum shared in the central and South Andean area.

Key words: cross-linguistic, Mapudungun, ritual language, Andean languages

\section{INTRODUCCIÓN}

El universo semántico de la ritualidad mapuche es uno de los dominios léxicos más ricos en el registro de relaciones translingüísticas andinas (Moulian y Catrileo 2013). En él se activan y movilizan 'constelaciones semióticas' que son comunes a las culturas de este espacio, es decir, series de relaciones de significación que dan forma a representaciones sociales compartidas. Su estudio permite seguir el devenir de los procesos interculturales prehispánicos y constituye una vía para la reconstrucción de la etnohistoria mapuche. Éste es, precisamente, el objetivo del presente trabajo: poner en evidencia los procesos históricos de interacción cultural en las áreas centro y sur andinas que dejan su impronta la cultura mapuche. Para ello, abordamos contextualmente los correlatos andinos en los repertorios lingüísticos de la ritualidad mapuche. Nuestra atención se focaliza en el registro de voces rituales cuyos enunciados muestran semejanzas fonéticas y semánticas, las que analizamos atendiendo a sus contenidos simbólicos y las relaciones sociales interculturales que en ellas se encuentran implicadas.

Por 'lenguaje ritual' entendemos aquí a los repertorios léxicos que se articulan en los escenarios donde se desarrollan las prácticas simbólicas religiosas o sociales (Moulian 2005, 2008, 2012; Catrileo 2014). Éste comprende términos sagrados, conceptos cosmovisionarios, marcadores identitarios, pautas de sociabilidad, patrones de comensalidad 
y los recursos que se consumen en el marco de estas prácticas sociales. En su dominio léxico participan campos semánticos como 'religión y creencia', 'vestuario y adornos', 'relaciones sociales y políticas' y 'comidas y bebidas', identificados en la literatura por Tadmor (2009) como propicios para la incorporación de voces ajenas. De ellos, el campo correspondiente a 'creencia y religión' es el que registra un mayor índice relativo de préstamos lingüísticos, según lo señala la encuesta translingüística de Haspelmath y Tadmor (2009). Los datos de nuestra investigación muestran las prácticas rituales como instancias de mediación intercultural, lo que se evidencia en la apertura y receptividad de sus ámbitos léxicos para la incorporación de préstamos lingüísticos.

Los estudios precedentes sobre relaciones translingüísticas andinas en el mapudungun asumen una perspectiva general. Patrón (1912) estudia la influencia del quechua sobre la lengua y la cultura mapuche en campos como la toponimia, zoonimia, fitonimia, minería, culinaria y corporalidad. Englert (1934) ofrece un repertorio organizado alfabéticamente de voces quechuas y aymaras registrados en la lengua mapuche. Del mismo modo procede Díaz-Fernández (1992), quien identifica transferencias de las lenguas quechua y yunga. Un trabajo previo de nuestra autoría (Moulian, Catrileo y Landeo 2015) aborda los afines quechua en el Vocabulario de la Lengua de Chile de Luis de Valdivia (1887 [1606]). Éste provee un punto de referencia temporal en el registro de los préstamos lingüísticos. En el presente artículo nos focalizamos en el estudio de las relaciones translingüísticas andinas en el lenguaje ritual, porque los antecedentes muestran que estas prácticas sociales y religiosas han servido como instancias de mediación intercultural. Su repertorio léxico registra el contacto. Los datos del contexto lingüístico permiten estimar su profundidad histórica.

\section{Presentación y análisis de resultados}

El método de investigación que empleamos en nuestro estudio es el análisis de correlaciones de 'constelaciones semióticas', entendiendo por éstas a las series de relaciones de significación que permiten el uso e interpretación de los signos. Nuestras unidades de análisis son constelaciones semióticas de términos del lenguaje ritual mapuche williche que presentan afinidades translingüísticas andinas. Dicho de otro modo, estudiamos los términos afines en el marco de las redes semióticas que los hacen operativos.

El concepto de 'constelaciones semióticas' se funda en el principio de interpretancia de Peirce (1965), según el cual lo que garantiza el funcionamiento de los signos es su derivación en otros signos que permiten su lectura. Se denomina 'interpretantes' a estos signos equivalentes que realizan la definición o traducción del signo primero. En tanto entidades semióticas, el funcionamiento de los interpretantes, a su vez, supone su remisión a otros signos que permite su interpretación y así sucesivamente en un proceso teóricamente ilimitado de encadenamiento semiótico. No obstante, como argumenta Eco (1992), en la práctica los procesos de interpretación comprometen un conjunto de relaciones de 
significación que se consideran pertinentes y relevantes para la lectura y uso de las unidades de sentido. Estas tramas de relaciones de significación que permiten el funcionamiento de los signos es lo que aquí denominamos 'constelaciones semióticas'. Evidentemente, no se trata de entidades semióticas fijas, sino variables en relación con la profundidad del campo interpretativo que se considere necesario para acceder a las representaciones sociales de los contenidos de la comunicación.

En términos operativos, el análisis de las constelaciones semióticas supone seguir el funcionamiento en red de los signos en dos dominios: el del sistema de la lengua y el de los saberes y prácticas culturales contextualmente situados. El primer eje es el de la lengua, sistema de modelización primario, donde se encuentran las relaciones de significación codificadas y se establece el valor de los signos en el marco de los paradigmas lingüísticos en que se inscriben. El segundo eje de relación es el de la cultura, donde operan procesos de modelización secundarios y se configuran las representaciones sociales contextualizadas. Las constelaciones semióticas, así consideradas, muestran la articulación de los diversos niveles de modelización, en el sentido de Lotman (1996), definidas en el plano de las lenguas naturales y de las prácticas de uso en dominios institucionales socialmente situados. Su estudio asume, en nuestro trabajo, un carácter comparativo. El análisis translingüístico de correlaciones en las constelaciones semióticas indaga en las semejanzas formales y de contenido de series de relaciones de significación que operan en torno a términos afines registrados en distintas lenguas andinas. Dado el carácter convencional de los procesos de modelación semiótica, regulados por los principios de arbitrariedad lingüística (Saussure 1945) y de relativismo cultural (Boas 1887), la correlación en las constelaciones semióticas constituye un indicador de relaciones interculturales.

En términos procedimentales, nuestro trabajo se inicia con la búsqueda de afinidades translingüísticas andinas de las voces del lenguaje ritual mapuche williche. Por 'afines' entendemos las voces de una lengua que presentan semejanzas de forma y contenido respecto de las de otro idioma. Las lenguas consideradas en este estudio son el quechua en su variante sureña, el aymara, el puquina, el kallawaya, el chipaya, el kunza y el mapudungun. Nuestra delimitación al estudio de las relaciones translingüísticas andinas se debe al hallazgo de afines lingüísticos quechua-mapudungun en el lenguaje ritual mapuche (Moulian y Catrileo 2013), presentes igualmente en el aymara (Moulian, Catrileo y Landeo 2015). Estudios precedentes señalan igualmente esta relacionalidad (Lenz 1905-1910, Patrón 1912, Englert 1934, Greenberg 1987, Díaz-Fernández 1992, Golluscio 2009). En la constitución del corpus han contribuido los resultados de un trabajo previo sobre los afines quechua en el Vocabulario de la Lengua de Chile del Padre Luis de Valdivia (Moulian, Catrileo y Landeo 2015). Este repertorio se ha visto enriquecido gracias a la experiencia etnográfica y lingüística de los miembros del equipo de investigación.

Cada vez que identificamos un término afín rastreamos su presencia en el repertorio de lenguas considerado como nuestro universo de estudio, de modo de establecer la extensión de su registro. La indagación en las constelaciones semióticas de estas voces, en las lenguas y culturas de referencia, es el paso consecutivo, tendiente al análisis de sus correlaciones. 
Por último, para la discusión de la profundidad histórica de los datos, la información del contexto lingüístico y cultural se analiza a la luz de los antecedentes disponibles sobre los procesos sociales andinos. Por esta vía, procuramos identificar estratos lingüísticos de afines andinos atribuibles a diversos períodos históricos, entendiendo por 'estrato' al conjunto de los elementos lingüísticos incorporados en el mismo momento. En este marco, se entiende que los estratos precedentes constituyen el sustrato cultural para los procesos de contacto posteriores. Los datos etnográficos que empleamos provienen de la experiencia de campo de los autores. En el caso del autor principal, ésta se funda en una experiencia de observación participante en rogativas del área Lanco y Panguipulli entre los años 2006-2008 y en un trabajo sistemático de investigación de la ritualidad williche del área de Lago Ranco y Río Bueno entre los años 1998-2008(Moulian 2005, 2012). En el caso de las dos coautoras de origen mapuche, ésta se funda en su experiencia de vida, como hablantes del mapudungun como primera lengua, participantes e investigadoras de su cultura. Esta información se complementa con datos etnográficos provenientes de la literatura sobre el tema.

\section{KAMARIKU Y KAMARIKUN}

La voz kamarikun (/kảmari,kun/) $)^{2}$ es uno de los términos empleados en mapudungun para designar a las ceremonias comunitarias mapuche de carácter social y religioso (Catrileo 1995). En el área de Panguipulli y Calafquén se emplea como sinónimo ngillatun, ritual colectivo de carácter sacrificial que se realiza para propiciación de solicitudes y agradecimiento de dones concedidos (Kuramochi y Nass 1989, Kuramochi y Huisca 1997). Este término se traduce, habitualmente, como 'rogativa'. Con el mismo sentido se usa la palabra kamarikun en el territorio mapuche oriental o puelmapu, especialmente en las provincias argentinas de Río Negro y Chubut (Casamiquela 1964). La forma castellanizada es 'camaruco' (Petit y Álvarez 2014).

En tanto expresión ritual regulada de acuerdo a normas tradicionales de larga duración, el kamarikun constituye un dispositivo de memoria (Kuramochi y Huisca 1997, Moulian 2002). En él se reproducen los sistemas conceptuales que organizan el pensamiento mapuche, las representaciones cosmovisionarias, las pautas que dan forma al culto, los códigos de sociabilidad, vestuario y culinaria. Desde esta perspectiva, es conservador. En tanto práctica social inscrita en los procesos de transformación de la sociedad mapuche, constituye también un testigo histórico, que opera como dispositivo de reflexividad de los procesos sociales en los que participa. Por este motivo, se muestra sensible al cambio. El propio nombre del ritual nos da cuenta de ello, porque -como advierten Lenz (1905-1910), Englert (1934), Erize (1960), Casamiquela (1964), Schindler (2006), Sánchez (2010)- es de origen quechua.

\footnotetext{
${ }^{2}$ En el presente trabajo sólo ofrecemos las transcripciones lingüísticas de los términos de las lenguas andinas que muestran afinidad en forma y contenido. Para ello empleamos el alfabeto fonético americano.
} 
En esta lengua, el término 'kamariku' (/kamảriku/) designa una obligación o imposición, una carga o impuesto (Rosat 2009: 494) o, según Grájeda (2013: 348), una "exigencia moral que rige la voluntad para aceptar una disposición". La voz se compone de la raíz kama (/'kama/) y los sufijos - ri y - $k u$. Según Garcilaso de la Vega, su radical significa "animar" (2012: 107), "dar alma, vida, ser sustancia" (2012: 171). Los evangelizadores coloniales le atribuyeron a esta voz el sentido de 'crear'. No obstante, Taylor (2000) ha mostrado que ello excede el marco de comprensión del término quechua que se compone del verbo ser, $k a$, que denota 'existencia', y el marcador de orientación - $m u$. De acuerdo a este autor, el concepto designa "transmitir una fuerza vital y sostenerla" (2000: 7), lo que, como apunta (Itier 2013: 10), implica "comunicar su ser a". Según Salomon (1991: 45), también "dar forma y fuerza".

El radical kama se expresa en una extensa serie léxica de carácter religioso y político. Kamaq (/'kamax/) designa a la "fuerza que anima" (Taylor 2000: 5) o que actúa como un poder ordenador. En palabras de Taylor (2001: 19), "entidad sagrada que transmite la fuerza vital a personas u objetos para que realicen la función que les corresponda”. El término también se emplea para significar 'poder' o 'autoridad'. Kamasqa (/ka’masqa/) es quien recibe la energía vital y se vuelve de ese modo 'animado', donde el sufijo -sqa resulta equivalente al participio. La idea de 'fuerza' se expresa también en la voz aymara kamasa (/ka'masa/) que designa el 'coraje' (Valda 1964: 30), 'aliento', 'valor' (de Lucca 1983: 217). En quechua, -kamayoq (/ka'mayox/) es la persona a quien el kamaq le ha dado la capacidad y conocimiento para desempeñar una tarea u ocupación (Taylor 2001). El término, pospuesto en relación a un sustantivo, designa 'oficio', al igual que el aymara -kamana (/kảmana/) (Bertonio 2011: 376). En tanto, en puquina, kama es 'oficio' (Torero 1987: 245).

La voz quechua kamariku (/kama’riku/) se inscribe en el paradigma lingüístico de esta lengua, previamente reseñado. En ella, el sufijo $-r i$ es incoativo e implica una exhortación. El sufijo $-k u$ es reflexivo (Cusihuaman 2001). La palabra kamariku designa a las obligaciones que se imponen a quien conoce al kamaq, fuente animadora o poder ordenador. El termino kamari (/kảmari/) denota "regalo, presente, obsequio a superiores, sacrificio" (Rosat 2009: 494) ${ }^{3}$. Kamarikuk (/kama’rikox/) significa 'disponerse para emprender una tarea'. En aymara, kamaräña (/kama’ra:ŷa/) significa 'aparejar todo lo que es menester'; kamaräsiña (/ka,mara:'sin̄a/), 'aparejarse' (Bertonio 2011: 376), es decir, prepararse, prevenirse, disponerse.

Juan de Matienzo (1910: 5 [1567]) refiere a "los camaricos ó presentes que los Indios dan a los apoes" en alusión a la práctica de la entrega de ofrenda en la mediación de las relaciones con las autoridades. Titu Cusi Yupanqui (1916: 79 [1570]) también emplea el término con ese sentido específico. Según el cronista inca, antes de retirarse al Antisuyo, Manco Capac recomienda a sus seguidores dar a los españoles "algún camarico"

\footnotetext{
${ }^{3}$ Las connotaciones religiosas y políticas de las voces con la raíz kama también se encuentran en la lengua Chipaya, donde kamacha es el lugar sagrado para las ofrendas, kamana es el altar doméstico, kaman-para, el bastón de mando de los alcaldes.
} 
como estrategia de consentimiento. El kamariku (o 'camarico') es aquí un medio de reconocimiento político.

Según muestra Rostworowski (2005), la "dávida” y el "ruego" son recursos básicos en el juego comunicativo de las relaciones sociopolíticas en el incario, que se desarrollan en el marco de encuentros ritualizados. Estos forman parte integral de la estrategia de expansión de Tawantinsuyo que combina la persuasión militar y la seducción ritual, como sistema de alianza alternativo al sometimiento por las armas. Establecida la autoridad del inca, el término kamariku nombra también a uno de los mecanismos de tributación de mano de obra, productos y objetos. Así lo informan las visitas de la Provincia de León de Huánuco en 1562 (Ortiz de Zúńiga 1967-1972 [1562]) y de Colic o Collique en 1571 (Mori y Soto Malpartida 1955-1956). Esta práctica se mantiene en el período colonial al servicio de los españoles.

Guamán Poma de Ayala (1980 [1615]: 257) testimonia que a lo largo del Camino Inca o Qhapaq Nan, cada provincia de su jurisdicción hacía su camarico y daba recaudo a principales y capitanes". La extensión de esta pauta permite explicar la presencia de topónimos con la voz 'camarico' en el espacio correspondiente Collasuyo. Con este término se conoce a una localidad de la Provincia de Maule en la VI Región de Chile, a un pueblo de la Provincia de Ovalle en la IV Región; en Argentina, a un río en la Provincia de Mendoza sobre el que se construye el llamado 'Puente Inca'; a una localidad en la Provincia de San Juan; y a un río en la Provincia de Catamarca.

El Memorial de Charcas (en Claros 2011 [1582]) expone el funcionamiento de esta institución. En este documento, representantes de las agrupaciones étnicas de Charcas, Caracaras, Chuis y Chichas reivindican ante la Corona su posición y derechos en Tawantinsuyo, como miembros del ejército imperial, cada uno de ellos con los trajes y hábitos distintivos de sus naciones. Según su testimonio (2011 [1582]: 47), por su condición "en cada pueblo y tambo les hacían mita y camarico como soldados de los ingas, ansi en dar comidas y la bebida y charques y ojotas, uestidos y mucha harina de quinoa y ganado y mujeres y los demás auiamientos y peltrechos como a soldados de los ingas". El informe documenta la incorporación de las diversas naciones en el sistema imperial. Guerreros procedentes del territorio chileno se hicieron parte del mismo, participando en el bando de Huáscar en la guerra de sucesión contra su hermano Atahualpa (Cabello de Balboa 1840 [1586]). Como soldados extranjeros, no sólo han debido hacer kamariku, sino también haberlo recibido. Si bien las crónicas no especifican la identidad étnica de este contingente, dada la importancia del valle del Mapocho como asentamiento inca y la cultura militar mapuche, podemos suponer su participación en estos eventos. Ramos Gavilán (1976 [1621]) informa sobre la peregrinación hasta Copacabana y los santuarios de las islas del Sol y de la Luna de personas venidas desde Chile, donde han debido hacer sus ofrendas.

Las fuentes metalingüísticas del mapudungun muestran la afinidad de las voces quechua y mapuche. Según Valdivia (1887: sp), se denomina 'camarico' "al tabo donde recibe al espańol y lo que le traen de regalo y para comer”. Para Febres (1765: 437), 'camarico' es 
"lo que traen de regalo al español". En tanto, "camaricun: hacer este regalo". De acuerdo a Erize (1960: 70), "camaricu: obligación impuesta a los indios de llevar alimentos y animales de carga a los incas en viaje, como así también lo que se les ofrece en tal ocasión. Los españoles siguieron esta costumbre con las poblaciones mapuche". Al respecto, este autor señala explícitamente que se trata de una "voz quechua mapuchizada".

Si bien el término quechua kamariku (/kama’riku/) es apropiado tempranamente por el discurso y las prácticas coloniales, su incorporación en el lenguaje ritual mapuche no se puede atribuir a una influencia hispana. Dos son nuestros argumentos al respecto. En primer lugar, porque en el contexto ceremonial religioso mapuche, la voz designa un proceso comunicativo que expresa las lógicas simbólicas propias del mundo andino. En segundo lugar, porque el préstamo de la voz no se produce de modo aislado, sino se inscribe en una serie lingüística adoptada del quechua cuyas otras voces no se inscriben en el discurso colonial hispano.

\section{Correlatos lingüísticos Y Rituales}

El término wün tiene una doble acepción en la lengua mapuche: significa boca y amanecer. En el contexto ritual del kamarikun, ambos sentidos se superponen, porque la llegada del día se recibe con la ofrenda de animales. La expresión küpa wün anuncia la llegada del día, momento en el que el sol abre su boca para dejar salir la luz al tiempo en que se alimenta (Kuramochi y Nass 1989). A medida que el astro sube, bajan al suelo las cabezas de las víctimas, a las que se les abre el pecho para arrancarles el corazón latiente. El procedimiento es el mismo que se emplea en la wilancha, como se denomina el sacrificio de animales entre quechua y aymara. En el lenguaje simbólico mapuche, al corazón ofrendado se le denomina llangka piwke (Augusta y Fraunhæusl 1910: 39, Alcamán y Araya 1993). Piwke es la voz que designa a este órgano vital. El término llangka (/lan'ka/), en tanto, es un quechuismo que significa de color marcado y que ha devenido en el mapudungun en sinónimo de sagrado. Con el corazón en la mano, el ngenpin, sacerdote mapuche, realiza sus oraciones en dirección al sol.

En el área cordillerana de los lagos Calafquén y Panguipulli, el término kamarikun designa a grandes rogativas en las que se congregan cuatro comunidades, las que de este modo conforman una unidad territorial ampliada, denominada kiñel mapun. Es la mayor y más importante expresión ritual en términos sociorreligiosos en este territorio. Cada año, una de las comunidades participantes organiza la ceremonia y hace de comunidad anfitriona, mientras las otras asisten como invitadas. Los años sucesivos se alternan los roles en un ciclo que se repite al cuarto ańo. El simbolismo tetralógico, común al mundo andino, se manifiesta aquí en el patrón de enunciación de las oraciones, que se despliegan en cuatro segmentos, y en la ejecución de las danzas alrededor del espacio ritual, con secuencias de cuatro giros, que se repiten en cuatro oportunidades. En otros sectores mapuche, como el área de Imperial y Puerto Saavedra, el término kamarikun designa las ceremonias 
intracomunitarias para agradecer anualmente las cosechas. Por lo común, ellas se realizan a fines del verano (walüng) o comienzos del otońo (rimü), entre los meses de marzo y abril.

En términos etnográficos, las zonas de Calafquén y Panguipulli son un reservorio cultural, un espacio donde se conservan las instituciones propias de la cultura mapuche. Esto se manifiesta con particular intensidad en el kamarikun, marcado por "un patrón cognitivo profundo de valoración del pasado" (Kuramochi y Nass 1989). El nombre del ritual forma parte de esta tradición de larga duración. En este contexto, se encuentran en uso otras voces de origen quechua, de temprana incorporación al mapudungun (Valdivia 1887). Un ejemplo es el término kamañ (/kảmañ/), perteneciente al mismo paradigma léxico que el anterior. Este lexema pospuesto, en relación a un sustantivo, designa oficio, ocupación. En el lenguaje ritual, ngillatunkamañ es el encargado de la rogativa; trutrukakamañ es el responsable de la ejecución de la trutruka, instrumento aerófono compuesto de una cańa y cono vegetal o cacho de vaca que sirve de amplificador. De acuerdo a la concepción mapuche, el desempeño de estas responsabilidades es un don y misión espiritual recibida de los ancestros, que no se puede rehuir. En quechua, el término afín es kamayuq (/kảmayox/) que, pospuesto, designa ocupación u oficio. Como ha mostrado Taylor (2000), la disposición y capacidad de ejercicio de un rol u ocupación se define por el kamaq o espíritu que anima a la persona. Las voces mapuche kamañ y quechua kamayuq denotan una profesión, connotan una vocación espiritual y se emplean en posposición. En tanto, en lengua aymara, el término kamana (/kảmana/), pospuesto en relación a un sustantivo, designa oficio. Para el puquina, kama es oficio (Torero 1987: 245).

En la cuenca del Río Bueno (Wenuleufü en mapudungun), situada al sur de los espacios previamente referidos, encontramos en uso las voces kamasko / kamaska (/ka’ma,sko/, /kảma,ska/), castellanizadas en la declinación de género, que denominan a los miembros de las congregaciones rituales mapuche williche. El término homólogo quechua kamasqa (/ka'masqa/) designa a quienes son receptores de la energía animadora de un kamaq (/'kamax/) particular. Como muestran los relatos de Huarochiri, esto genera identidades espirituales y vínculos rituales entre los kamasqa y los espíritus animantes. Algo similar sucede con los miembros de las congregaciones rituales mapuche williche del Wenuleufü. En esta área se mantiene activo el culto a espíritus ancestrales emplazados en la naturaleza, como Wenteyao, Kintuante y Juanico, quienes sirven como mediadores ante la divinidad y a los que se considera ngen mapu, dueños del territorio. Los kasmaskos peregrinan hasta la morada de estos espíritus y los propician en las rogativas para recibir su newen, fuerza vital. La lectura del término mapuche desde la lengua quechua resulta iluminadora del sentido de esta institución ritual.

\section{Códigos en contacto}

Las prácticas rituales mapuche se mantienen vigentes hasta el presente como espacios de reproducción cultural y autoafirmación identitaria. En ellas, se emplean los 
códigos vernáculos que registran las huellas de contactos ancestrales. La participación en el kamarikun exige el uso del vestuario tradicional mapuche. Los varones llevan makuñ, como se denomina a la manta, y chiripa (/čə’ri,pa/), pantalón de paño, elaborado a partir de una tela cuadrada que ponen entre las piernas de modo similar al pańal. El nombre de esta última prenda corresponde a un préstamo del quechua, que deriva de las voces chiri (/'čiri/) que designa 'frío' y pak (/pax/) que significa 'para' (Lafone 1898: 104, Lenz 19051910: 433-434, Catrileo 2006). Esta ropa se emplea extensamente entre los gauchos del área pampeana en la vertiente oriental de la Cordillera de los Andes.

El vestuario de las mujeres mapuche se compone del küpam, vestido compuesto de un pańo de color azul marino o negro que se prende con alfileres desde el hombro. Sobre éste llevan una ükülla /ə’kə,la/, chal o rebozo. En quechua encontramos la voz afín unkilla (/un'kila/) que, al igual que el término unku (/'unku/), designa a los tejidos de algodón u otras fibras vegetales (Rosat 2009: 1189-1190). Valdivia (1887 [1606)] escribe el término como yclla (/ik'la/), con elisión de la segunda vocal, a la que define como 'manta de indias'. Esta voz es bastante próxima a la palabra quechua lliclla (/'likla/), que designa a la 'manta de mujeres' (González de Holguín 2007: 152). Sólo difieren en la ausencia del fonema lateral palatal inicial en la voz mapuche. En caso de tratarse de una transformación diacrónica del término mapuche, ello podría indicar la vía del préstamo. Para usar la ükülla, ésta se prende frente al pecho con un tüpu (/tro’ pu/) o alfiler metálico con cabeza en forma de disco (Erize 1960: 388). La voz es de origen quechua (González de Holguín 2007 [1608]: 227, 255) y se escribe de manera homónima: tири (/'tupu/). La pieza metalúrgica que designa se encuentra registrada arqueológicamente en el espacio centro andino desde el período formativo tardío entre el 200-400 d. C. (Fernández 2015).

En el plano culinario, uno de los platos fundamentales que se prepara y comparte en el kamarikun es el asado o kankan (/kan'kan/). Como apunta Lenz (1905-1910), el término también proviene del quechua, donde se encuentra en las diversas variantes de esta lengua. González de Holguín (2007 [1608]: 61) registra las formas cancani (/kaך'kani/) para

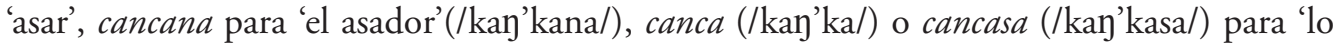
asado'. El radical de este término, no obstante, es compartido por el aymara. Como expone Bertonio (2011 [1612]: 376), en esta lengua kankasiña (/kạka’siña/) significa 'asarse', kankaña (/kay'kaŷa/) 'asador' y kanka (/'kayka/) 'asado'. En el jacaru, idioma de la familia aymara, que se habla en el área central del Perú, la voz kanki denota 'asar' (Belleza 1995: 89). En la lengua chipaya de Bolivia kanka (/'kayka/) significa 'asado' (Cerrón-Palomino y Ballón 2011: 204). En kunza, ckanckata es el término que expresa la 'acción de asar' (Vaïsse, Hoyos y Echeverría 1896: 16).

Valdivia (1887 [1606]: sp) consigna tempranamente en el vocabulario mapuche la presencia de las voces canca (/kan'ka/) con el significado de 'asar' y cancahue/kan'kawe/), con el de 'asador'. Si bien esta lengua dispone de las voces kuen, kuchen (Augusta 1916: 96-97), cupun (Cañas 1911: 262) como sinónimos para el verbo asar, la forma kankan (/kan'kan/) asume un uso predominante. La serie léxica asociada a ésta incluye los términos que se han incorporado al lenguaje popular, como cancagua, que designa a una piedra 
arenisca aplanada que se emplea en los fogones y cancato, nombre del pescado asado, que se suele rellenar con longaniza. El registro translingüístico que asume la voz quechua y su incorporación al mapudungun se puede explicar por el contacto con las tropas del ejército inca. Entre sus prácticas alimenticias, éstas acostumbran el consumo de carne asada, tanto de los hatos de animales que transporta como del ganado que reciben en kamariko (Bram 1977). Ello permite el acceso a una fuente fresca de proteínas y da lugar a prácticas de comensalidad ritual.

La principal bebida que se consume en la actualidad en las rogativas mapuche es el muday (/mu'Өay/), como se denomina a la chicha de trigo cocido. El término se empleaba en el pasado para designar a la chicha de maíz, cuyos granos se mascaban para hacerlos fermentar (Joseph 1931). En quechua, mujchay (/'muxčay/) es desgranar el maíz (Rosat 2009: 707). En aymara, el término muxch'i (/'muxči/) designa al 'maíz mascado'; muxchiña (/'muxčina a/), es 'mascar el maíz para hacer chicha' (Bertonio 2011: 412). En la cultura mapuche, este procedimiento se mantiene vigente hasta el día de hoy para preparar una chicha denominada mushka (/mus'ka/) que se emplea sólo con fines rituales, para asperjarla en las oraciones que se realizan en el rewe o espacio sagrado. En quechua, muk'u (/'muku/) es 'el maíz para la preparación de la chicha llamada mascada'; mukuchiy (/'mukuči:/), 'hacer mascar maíz' (Middendorf 1890: 600). En aymara, muq’uña (/'moqoồa) también significa 'mascar el maíz para la chicha' (Bertonio 2011: 412). Cabe destacar que la evidencia de consumo de maíz en la Patagonia nororiental ha sido datada a partir del año $1.000 \mathrm{~d}$. C. (Pérez y Erra 2011), la que ha sido documentada a través del estudio de fitolitos en contenedores cerámicos.

Entre los rituales de sociabilidad que se desarrollan en el marco de las rogativas mapuche destaca el konchotun (Augusta y Fraunhæusl 1910: 38; 1916: 93). El término designa en mapudungun a una ceremonia que se realiza para sellar o reafirmar una relación de amistad entre dos varones que sacrifican un cordero juntos, intercambian regalos, discursos solemnes y beben de un mismo cántaro, hasta acabar su contenido. El título de koncho (/kon'čo/) que significa 'amigo, compañero' (Monart 2005) se lo dan mutuamente quienes han participado de esta ritualidad, que establece una relación de afinidad social que compromete a sus miembros. Koncho es, igualmente, el término que designa a la borra o residuo de la chicha (Febres 1765: 459-460). Entre las dos acepciones hay una relación metonímica porque son koncho las personas que han bebido juntas hasta el koncho. En este contexto, el beber juntos es relevante porque implica el depósito de confianza en el otro, presupuesto en que la bebida no tiene daño. Hasta el día de hoy, cuando los mapuche se reúnen a beber se puede escuchar la expresión "entukünunge mi kalku" que significa "sacar primero el kalku" en alusión a las malas intenciones que pueden estar detrás. Por lo mismo, beber en el mismo jarro es una forma de garantizar la confianza. De este modo, la bebida puede cumplir la función de intensificar las relaciones sociales, ampliamente etnografiada en el contexto andino (Jennings y Bowser 2009).

En aymara encontramos una serie léxica afín en forma y contenido al concepto mapuche de koncho. La voz koncha quncha (/kon'ča/ /qun'ča/) designa a 'amigo, camarada' 
(de Lucca 1983: 232), también definido como "el amigo con el que suele beber y holgarse" (Bertonio 2011[1612]: 451). En esta lengua, konchaña (/kon,čàña/) denota "brindar, beber a la salud de alguno' (de Lucca 1983: 232); konchasiña qunchasiña (/končảsiña/ / qunčasiña/) es 'beber con un amigo o camarada' (de Lucca 1983: 232) o bien 'servicio entre ambos en una ceremonia' (Condori 2016); también 'brindarse las parcialidades y los ayllus' (Bertonio 2011: 104). Qunchu (/'qoncho/) designa al 'asiento o haz del vino', qunchukama umaña es "beber hasta el fondo del cántaro". Quñchuñ uru es el día de brindar, "penúltimo día de la fiesta, en el cual se realiza un encuentro amistoso entre distintas bandas que realizan el encuentro festivo" (van den Berg 1985: 161).

\section{INSTRUMENTOS SIMBÓLICOS}

Los elementos en uso en los contextos rituales asumen un carácter simbólico, porque en ellos predomina su carácter significante por sobre las funciones operativas. Un ejemplo de ello es el de la makana (/ma'kana/), elemento distintivo del rol de los 'sargentos', como se denomina a los encargados de impartir las órdenes en las rogativas (Kuramochi y Nass 1989). Ésta consiste en una vara de madera aguzada de cerca de dos metros, con la que se puede golpear a quienes infrinjan los códigos de la rogativa. El término deriva del verbo quechua maqay (/'maqay/) que significa 'golpear' y del sustantivo maqana makana (/ma'qana/ /ma'kana/), 'garrote grueso de madera dura' (Rosat 2009: 674) que designa a una porra o maza, empleada como arma de los soldados incas. En el kamarikun la makana es símbolo de la autoridad responsable de mantener las normas sociales. Como tal, se la riega con la sangre de los animales inmolados.

En las rogativas williche de Lago Ranco y Río Bueno, denominadas lepün, la makana ha devenido en emblema de las kamaska. Con este nombre se designa a las mujeres encargadas del trabajo de cocina en las ramadas o ranchos que cobijan a los distintos grupos familiares que participan en el ritual. Cada kamaska tiene su makana, que se sitúa en el rewe o espacio sagrado, adornada con las flores y frutos de sus huertas, marcando la posición que ocupa durante las oraciones. El desplazamiento en el uso ritual de este instrumento probablemente expresa la costumbre de las mujeres de velar las armas de sus varones al momento de ir a la guerra. En este mismo contexto, las banderas rituales de las congregaciones reciben el nombre de wipala (/wi'pala/), término que se encuentra en el quechua y aymara bajo la forma wiphala (/wi $\left.\mathrm{p}^{h} \mathrm{ala} /\right)$ con idéntica designación. Las banderas williche son, generalmente, de paño azul y llevan inscrito sobre fondo blanco el diseño de referentes astronómicos como lunas y estrellas. Cada congregación ritual tiene como elemento distintivo su propia wipala.

En el campo de la funebria, las llangka (/lan'ka/) son instrumentos simbólicos a los que se atribuye un enorme valor, porque con ellas se paga por la muerte causada a otros, evitando de este modo las represalias, y se costea el paso de la propia alma hacia la otra vida. Ellas se encuentran registradas arqueológicamente en el contexto de ajuares mortuorios 
(Gordon 1978), como parte del equipamiento para el viaje hacia el otro mundo. Se trata de unas pequeñas piedras de color verde azuloso, que contienen nitrato o sulfato de cobre. Su cromatismo azulado les asigna un carácter sagrado, a la vez que las vincula con el uso quechua del término. En esta lengua, llank'ay (/'lank'ay/) significa 'trabajar' y en el lenguaje ritual chamánico denota a la capacidad por parte de los médicos-sacerdotes para realizar su trabajo espiritual (Wilkox 2004: 320, Delgado y Male 2009). En tanto, el término llanka llak'a (/'lanka/ /'lanka/) se emplea asociado a sustantivos que indican color, para señalar que éste es subido de tono, nítido, bien marcado (Rosat 2009: 615). Esta marca de intensidad cromática es lo que hace 'trabajar' a los colores en la estética andina e indica 'fineza'. Llanka puka, por ejemplo, es bermejo o rojo intenso. En aymara, llanko (/'lanko/) denota muy negro. El mapudungun registra un uso similar en el término llancavu llangkavu (Valdivia 1887: sp) que significa 'morado'. La voz connota una capacidad operativa que se expresa en una serie léxica. Llangkañ designa al ayudante que trabaja con la machi, como asistente ritual. Llangka piwke es el corazón de los animales sacrificados en las rogativas, órgano que opera como mediador en procesos de transacción simbólica. Llangka foro es la denominación de la clavícula, hueso que tiene un papel fundamental en el sistema articulatorio de los brazos. Malwellangka es el cántaro ritual con el que se predice el tipo de cosechas que se obtendrá.

En el ámbito de la funebria mapuche se encuentra, igualmente, la voz wampo (/wam'po/), perteneciente a los repertorios léxicos del quechua (wampo, /wampo/) y del aymara (wampo, /wampo/), que significa 'canoa'. En el contexto mapuche, además de este sentido, designa a contenedores mortuorios labrados en corteza de árbol. Una de las creencias escatológicas predominantes en el mundo mapuche es que tras la muerte los espíritus navegan por los ríos hacia el mar, donde deben cruzar hasta una isla (Guevara 1908, Latcham 1924). Por lo mismo, se emplea el wampo como contenedor fúnebre. La concepción del viaje fluvial se registra en la costa de Arauco, en el área lelfunche de la cuenca del Río Bueno y Chiloé. Sus representaciones son compartidas en el área costera centro y sur peruana, donde las almas parten hacia la otra vida por el océano (Negro 1996, Millones 2010). En el contexto arqueológico mapuche, el uso de las canoas como medio de enterratorio data de $1280+-80 \mathrm{~d}$. C. (Gordon 1978), es decir, desde antes de la llegada del inca a la zona central de Chile, cuya estimación más temprana se cifra en torno 1390 d. C., en base a termoluminiscencia de piezas cerámicas (Cornejo 2014). Valdivia no sólo registra este término en su Vocabulario de la Lengua de Chile (1887 [1606)], sino la voz derivada wampelleun wampüllüwün, con el significado de 'velar', refuerza la evidencia de su temprana incorporación en las prácticas rituales mortuorias.

\section{Símbolos NATURALES}

La cultura mapuche organiza las coordenadas del espacio y tiempo simbólicos a partir de los ciclos del sol y de la luna, reproduciendo una matriz que resulta común al mundo andino. Las canchas de rogativa se orientan hacia el oriente, desde donde nace el 
sol. El amanecer es un momento de intensificación de la actividad ritual, cuando se ofrecen las oraciones y sacrificios en dirección al astro. El movimiento de las personas, el giro de los bailes, el desplazamiento de las cabalgaduras en el espacio ritual se realiza de derecha a izquierda, reproduciendo el movimiento figurativo del sol en el curso horario. En tanto, las prácticas fúnebres suponen un movimiento predominante de las almas en dirección oeste, hacia la puesta del sol. Los muertos continúan viviendo en el mundo dominado por la noche, donde el astro dominante es la luna, concebida como opuesta complementaria del sol.

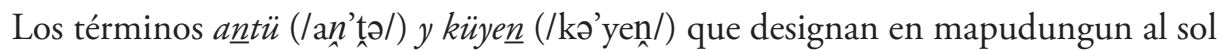
y la luna presentan evidentes homologías formales con las voces quechua inti (/'inti/) y killa (/'kila/), que tienen la misma designación. Las variantes puelche anti (/an'ti/) y williche killen (/ki'len/) son aún más próximas. Más importante aún, el análisis de las representaciones de los astros en el mundo andino deja en evidencia una serie de correlaciones en sus constelaciones semióticas. Como advirtiera Lehmann-Nitsche (1919), la concepción de los astros es compartida en el espacio andino. La visión de estos en la cultura inca, que se proyecta en las comunidades quechuas contemporáneas, y las nociones prevalecientes entre los aymara y los mapuche, son similares. En estas culturas persiste la imagen del sol y de la luna como una pareja divina, donde el sol asume el rol masculino y la luna el femenino, vinculados a través de una alianza conyugal que tiene como progenie a los luceros del atardecer y el amanecer, con quienes forman una familia.

En la configuración de las representaciones de los astros se combinan aquí concepciones teológicas, de género y filiación. Dado el carácter patrilineal del orden social, al sol se le otorga un rol predominante, se le asigna un carácter reproductor y capacidad fertilizadora, se lo asocia a la vitalidad y se lo representa a la derecha. A la luna se la representa a la izquierda, se asocia a lo nocturno, a lo bajo, a los espíritus del otro lado de la vida y se la asocia a la fecundidad. Nos encontramos aquí con un sustrato ideológico compartido en el mundo andino, que sirve de marco para el desarrollo de las prácticas rituales. En el contexto amazónico, en cambio, se encuentra extendida una representación del sol y de la luna como hermanos mellizos varones (Blixen 2013). En el Chaco se considera a la luna como masculino y al sol femenino (Métraux 1946). Las constelaciones semióticas que configuran las representaciones sociales se diseñan allí de otro modo.

\section{Discusión}

El lenguaje ritual mapuche williche registra una notoria presencia de voces quechua y aymara. Parte de éstas se pueden explicar como préstamos lingüísticos resultantes del contacto con la lengua del imperio inca, denominada 'quechua imperial'. Al respecto, es relevante señalar que la voz inka ingka designa en mapudungun 'amigo', 'compañero'; el verbo inkan denota 'ayudar', inkatun significa 'pedir ayuda' (Febres 1765: 522, Erize 1960: 205). El significado de estas voces presupone una relación de 'alianza' con los ocupantes cusqueños. 
Ello es compatible con los datos etnohistóricos y arqueológicos que informan el asentamiento incaico en el valle del Mapocho, alrededor de 1390 (Cornejo 2014) y hasta 1536, cuando llega Diego de Almagro. Se establece aquí un sistema de convivencia intercultural y colaboración interétnica. Con respecto a su extensión geográfica, el río Maule ha sido identificado como el lugar del último pukara inca y el Biobío como límite de las avanzadas de los soldados del Tawantinsuyo. No obstante, Dillehay y Gordon (1998) plantean que al sur del mismo los incas desarrollan relaciones comerciales y culturales y un sistema de asentamientos dispersos en forma de archipiélagos territoriales. Las evidencias lingüísticas y arqueológicas de esta relación intercultural en el área de Purén y Lumaco, en la Región de la Araucanía, han sido documentadas por Dillehay (2011). Los antecedentes que aquí presentamos muestran que esta influencia alcanza una mayor extensión geográfica en latitud sur.

Varios de los afines analizados se encuentran consignados en el Vocabulario de la Lengua de Chile de Luis de Valdivia de 1606, que documenta su temprana incorporación al mapudungun. La disponibilidad de sinónimos en esta lengua avala la hipótesis del préstamo lingüístico. Es el caso de la voz kamarikun (/kảmari,kun/), afín al quechua kamariku (/kamảriku/) y al aymara kamaräña (/kama’ra:ŷa/), que en mapudungun equivale a ngillatun (rogativa) y trawun (encuentro ritual). El término -kamañ (/kảmañ/), afín al quechua -kamayuq (/ka’mayox/) y al aymara-kamana (/kảmana/), sustantivo que en posición pospuesta indica 'oficio', tiene en la lengua mapuche el mismo sentido y función que el sufijo sustantivizador -uve -ve. La palabra kankan (/kan'kan/), afín al quechua kankay (/'ka $\mathrm{kay} /$ ) y al aymara kankasiña (/kanka'siña/), significa 'asar' y es equivalente a kuchen o rekan. La voz ükulla iklla (/a'kə, la/ /ik'la/), afín al quechua unkilla (/un'kila/), refiere al rebozo femenino llamado en mapudungun, igualmente, $k u d u$ o choñe. Otro caso es wampo (/wam'po/), homónimo al quechua y aymara wampo (/'wampu/), que significa 'embarcación' y cuyos sinónimos son dalca (canoa) y trolof (contenedor fúnebre).

De modo similar sucede con otras voces omitidas en el Vocabulario de la Lengua del Reyno de Chile de Valdivia, como muday (/mu'Đay/), afín al quechua mujchay (/'muxčay/) y al aymara muxchi (/'muxči/), que en la lengua mapuche designa originalmente a la chicha de maíz también denominada uwapullku. La palabra muska (/mus'ka/), afín al quechua muk’u (/'muk'u/) y al aymara muq'uña (/'moqoña), que igualmente es sinónima de muday. El término makana (/ma'kana/), homónimo al quechua makana (/ma'kana/), que en el uso en contexto ritual mapuche refiere a una lanza o wayki. Chiripa (/čə’ri,pa/), afín al quechua chiripak (/'čiripax/), nombre de una pieza del vestuario masculino, compuesto de un pańo empleado en forma de pantalón y que registra como sinónimo la voz chamall. En todos estos casos, la existencia de sinónimos indica que la lengua mapuche incorpora nuevos términos para designar instituciones, conceptos o prácticas preexistentes al contacto lingüístico. La persistencia de los nombres vernáculos en el acervo idiomático es la evidencia de ello.

Cuando no se dispone en el mapudungun de sinónimos para los afines, los términos pueden ser neologismos, es decir, voces introducidas para designar un nuevo recurso cultural apropiado en el encuentro intercultural. Es el caso del tüpu (/ta’’pu/), homónimo 
del quechua tири (/'tupu/), que designa a una pieza de metalurgia compuesta de cabeza discoidal y punzón, la que cumple una función de alfiler. Su registro arqueológico en el contexto mapuche se remite al período de contacto hispánico (Campbell 2004, 2015). No obstante, esta pieza es parte de los repertorios materiales incaicos documentados para la zona central. Se encuentra, por ejemplo, en una figurilla de plata que compone el ajuar funerario de la momia del cerro El Plomo. La falta de sinonimia para el término wipala (/wi'pala/), voz homónima en el quechua y el aymara (/wi $\mathrm{p}^{\mathrm{h}} \mathrm{ala} /$ ), que designa a las banderas, podría indicar que se trata, igualmente, de un neologismo.

La situación resulta problemática cuando la institución o concepto designado por los términos afines corresponde a componentes culturales que se presupone prexistentes y no se encuentra un término propio del mapudungun, distinto del afín, que los designe. Es lo que sucede con los términos kamaska / kamasko (/kảmas,ko/, /kảmas,ka/), homónimos al quechua (/kảmasqa/). Una voz próxima en el mapudungun es elval, que significa 'encargado', 'depositario', pero no hemos encontrado registros de su uso en el contexto ritual. No obstante, consideramos inverosímil plantear que el culto a los espíritus ancestrales tutelares emplazados en el espacio, con el que se vincula la institución de los kamasko y las kamaska, se introduzca a partir del contacto inca. En primer lugar, porque la cultura inca es respetuosa de los cultos locales. En segundo, porque las variables temporales y geográficas no son consistentes con la hipótesis de una inculturación religiosa. El término presenta una distribución local entre el valle central y el área precordillerana de la cuenca del Río Bueno. Esta área se sitúa a quinientos quilómetros al sur de la frontera meridional del Tawantinsuyo, situada en el río Maule.

La voz koncho (/kon'čo/) es el único aymarismo (koncha, /'kunča/) registrado en el corpus consultado de afines rituales. El término lo encontramos por primera vez en Febres (1765) y no conocemos sinónimo para la relación social ritualmente establecida que designa. No obstante, la extensión de esta institución nos hace suponer que se trata de una voz antigua, por lo menos precedente al período de su registro escrito. Una posibilidad es su incorporación durante la expansión del Tawantinsuyu, porque el inca empleó en la constitución de su imperio soldados lupacas, carangas y soras, hablantes de lengua aymara. Del mismo modo sirvieron en su ejército soldados provenientes de Chile, probablemente mapuche-pikunche. En este contexto es posible que hayan combatido en conjunto y sostenido encuentros rituales.

Cuando los términos afines forman parte del vocabulario básico, la situación es más clara, como sucede con las voces antü y küyen, que designan al sol y la luna. Como no se registran sinónimos para estos términos, resulta inverosímil considerarlos préstamos lingüísticos tardíos, como los procedentes del quechua imperial. De ser éste el contexto del préstamo, deberían permanecer en el repertorio lingüístico los términos vernáculos que designan a estos astros, pues no se puede pretender que los mapuche carecieran de ellos. Dado que esto no ocurre, cabe considerar a estas voces cognados o bien préstamos arcaicos. Ambas alternativas indican la existencia de un estrato de relaciones interculturales andinas anteriores al Tawantinsuyo. 
En el caso de los términos antü y kuyen, no sólo se expresan afinidades lingüísticas con el quechua, sino correlaciones en las constelaciones semióticas andinas del sol y de la luna, documentadas para la cultura inca, aymara y mapuche. Dado que la incorporación de las voces desde el quechua imperial queda descartada, la hipótesis disponible más fuerte es la influencia puquina, lengua extinta en el siglo XIX. Hoy existe cierto consenso en la lingüística andina en torno a que ésta habría sido la lengua de Tiwanaku (Torero 1987, Bouysse-Cassagne 1987, Espinoza 1987, Aguiló 2000, Cerrón-Palomino 2013). Los datos sobre la irradiación de restos arqueológicos de esta cultura y los antecedentes etnohistóricos sobre la distribución de la lengua coinciden. Cerrón-Palomino (2013) sostiene que ésta habría sido la lengua secreta de la casta imperial incaica, cuyos miembros serían de origen tiawanakota. Por lo mismo, según este autor, el lenguaje institucional del incario contiene numerosos puquinismos en sus dimensiones política y religiosa. Uno de ellos es inti, término afín al mapuche antiü.

Como argumenta Cerrón-Palomino, el quechua sureño dispone de la voz punchaw para designar al astro (2013: 71-72). En el quechua central se registra como alternativa de inti el término rupay con la denotación de sol (Parker y Chávez 1976). El término inti, en tanto, es parte del repertorio puquina registrado por Oré (1607). Por otra parte, la voz killa, afín al mapuche küyen $\sim$ killen, se compone de la partícula '-illa', de probable filiación puquina (Aguiló 2000). Ésta se encuentra presente en diversos términos que designan a los astros en la lengua quechua como k'atu illa, katachillay (Rosat 2009), con los que se nombra al planeta Mercurio y a la constelación de la Cruz del Sur, respectivamente.

La migración lingüística del puquina puede explicarse contextualmente como resultado del colapso ambiental que afectó al área circundante al lago Titicaca, cuna del puquina, alrededor del año mil. Esto habría producido la caída de Tiwanako y la migración de sus habitantes hacia el norte, los que habrían fundado el incario. En tanto, el desplazamiento de la población puquina hacia el sur incidiría en el aumento de la complejidad social en esta área. Cabe señalar que en el mismo período comienzan en la Araucanía las prácticas de monumentalización del paisaje y de la agricultura intensiva (Dillehay et al. 2007).

Los datos lingüísticos expuestos dan cuenta de la existencia de un correlato ideológico en torno a las representaciones del sol y de la luna que son anteriores al incario. No se trata de un hecho aislado. En un trabajo anterior también lo hemos documentado para las constelaciones semióticas del brillo, que muestran una concepción común de la luz como forma de energía primordial de carácter animante (Moulian et al. 2018). La existencia de este sustrato cosmovisionario compartido abre una vía de explicación para la incorporación de voces cuyo estatus histórico-lingüístico resulta difícil de discernir. Es el caso del término llangka (/lan'ka/), homónimo al quechua llanka (/'lạka/), y que designa en mapudungun a las piedras con que se paga el paso a la otra vida y ha devenido en denotador de lo sagrado. No encontramos una voz sinónima en el mapudungun con igual extensión semántica; además, no se dispone de un objeto simbólico con usos equivalentes. La incorporación de este lexema al mapudungun presupone una concepción compartida en el mundo andino de la capacidad operativa de las piedras, asociada, en este caso, a las marcas de intensidad del color, que funda su poder $y$ valor. 


\section{Conclusiones}

Los términos afines en el lenguaje ritual mapuche williche informan procesos históricos que modelan socioculturalmente a la región andina. De los datos lingüísticos, se desprende que en el desarrollo de estas relaciones interétnicas del área la ritualidad ha operado una doble articulación comunicativa: como mediador simbólico en el plano cultural, como mediador político en el plano social.

En el campo de las relaciones translingüísticas del lenguaje ritual mapuche williche, identificamos seis quechuismos (chiripa, llangka, kamaska, makana, muday, tüpu, ükülla), siete afines quechua y aymara (kankan, kamariko, kamañ, muday, muska, wampo, wipala), un aymarismo (koncho), un puquinismo (antü) y una voz posiblemente derivada del puquina (küyen). El análisis del contexto lingüístico e histórico permite distinguir en este repertorio dos estratos de correlaciones léxicas correspondientes a distintos momentos de contacto lingüístico e interacción cultural. Un estrato conformado por préstamos lingüísticos del quechua atribuibles a la fase de expansión imperial inca. Un estrato léxico que muestra, igualmente, relaciones translingüísticas con el quechua, pero que no se puede atribuir al contacto con el Tawantinsuyo y cuyas correlaciones presuponen mayor profundidad histórica.

El primer estrato, más reciente en términos temporales, se encuentra conformado por los quechuismos, los afines presentes tanto en el quechua como en el aymara y el aymarismo. Es el estrato que presenta mayor representatividad y se encuentra más claramente definido. Su asociación al incario permite explicar la extensión de algunas de estas voces a otras lenguas, como la chipaya y la kunza. Los casos de doble adscripción al quechua y al aymara expresan la larga asociación entre estas lenguas que comparten un extenso repertorio léxico. En cuanto a la distribución geográfica de las voces, la mayor parte desborda las áreas de influencia directa del Tawantinsuyo. Un caso conspicuo es el término kamaska, circunscrito a un uso regional en un territorio situado a quinientos kilómetros de la frontera meridional del incario.

El segundo estrato, más antiguo, se encuentra formado sólo por dos voces, pero que tienen una enorme importancia simbólica, porque designan a los astros predominantes en el espacio sidéreo de nuestro planeta. Si bien los términos también presentan afinidades con el quechua, no se puede explicar su presencia en el mapudungun como influencia de esta lengua porque no se encuentran sinónimos para ellos en el mapudungun. De tratarse de préstamos, deberían quedar en el registro lingüístico las voces vernáculas que designan al sol y la luna. De su inexistencia se infiere que los afines muestran una deriva común o son préstamos arcaicos. La hipótesis más fuerte que disponemos para explicar la presencia de estas afinidades es la puquina, que sabemos ha improntado al quechua institucional y puede haber llegado al sur en una migración asociada a la diáspora de Tiwanako.

El análisis de las constelaciones semióticas de los términos afines antü/inti y küyen/ killa, que hacen posible su funcionamiento y conforman sus representaciones sociales, muestran un marco de concepciones cosmovisionarias compartidas en el mundo andino, que 
es anterior al incario. Ellas modelan las coordenadas de espacio-tiempo y de configuración del mundo en que se desarrollan las prácticas rituales. La existencia de este sustrato cultural común que muestra profundidad histórica debe haber facilitado la incorporación de los préstamos del quechua imperial, puesto que estos se inscriben en una lógica compartida. El desarrollo del incario supone, a la luz de estos datos, una continuidad en los procesos de andinización del espacio mapuche, que presenta larga data. El lenguaje ritual mapuche williche vigente en las prácticas socioculturales y religiosas muestra esta relacionalidad cultural.

\section{OBRas CITADAS}

Alcamán, Severino y Jorge Araya. 1993. Manifestaciones culturales y religiosas del pueblo mapuche. Temuco: Fundación Instituto Indígena.

Aguiló, Federico. 2000. El idioma del pueblo puquina: un enigma que va aclarándose. Quito: Fondo Ecuatoriano Populorum Progressio y Universidad Intercultural de las Nacionalidades y Pueblos Indígenas.

Augusta, Félix y Sigifredo Fraunhæusl. 1910. Lecturas araucanas. Valdivia: Imprenta de la Prefectura Apostólica.

Augusta, Félix. 1916. Diccionario español-araucano y araucano-español: Tomo primero. Araucano-Español. Santiago: Imprenta Universitaria.

Bertonio, Ludovico. 2011. Transcripción del vocabulario de la lengua aymara. La Paz: Instituto de Lenguas y Literaturas Andino-Amazónicas.

Belleza, Neli. 1995. Vocabulario jacaru-castellano, castellano jacaru. Cusco: Centro de Estudios Bartolomé de Las Casas.

Blixen, Olaf. 2013. La luz y las tinieblas. El día y la noche en la mitología sudamericana. Buenos Aires: CIAFIC Ediciones.

Boas, Franz. 1887. "Museums of ethnology and their classifications". Science 9: 589: $587-$ 589.

Bouysse-Cassagne, Thérèse. 1987. La identidad aymara: Aproximación histórica (siglo XV, siglo XVI). La Paz: Hisbol / IFEA.

Bram, Joseph. 1977. Análisis del militarismo incaico. Lima: Universidad Nacional Mayor de San Marcos.

Cabello de Balboa, Miguel. 1840 [1586]. Histoire du Péruo. Paris: Arthus Bertrand LibraireÉditeur.

Campbell, Roberto. 2004. El trabajo de metales en la Araucanía. (Siglos X-XVII d.C). Memoria para optar al título de arqueólogo. Santiago: Universidad de Chile.

Campbell, Roberto. 2015. "Entre El Vergel y la Platería Mapuche: El trabajo en metales en la Araucanía poscontacto (1550-1850 d.C.)". Chungará 47: 621-644.

Cañas, Alejandro. 1911. "Estudios de la lengua veliche". Trabajos del Cuarto Congreso Cientifico ( $1^{\circ}$ Pan Americano). Santiago: Imprenta Barcelona. Vol. 11: 143-330. 
Casamiquela, Rodolfo. 1964. Estudio del ngillatun y la religión araucana. Bahía Blanca: Universidad Nacional del Sur.

Catrileo, María. 1995. Diccionario lingüistico-etnográfico de la lengua mapuche. Santiago: Editorial Andrés Bello.

Catrileo, María. 2006. "Glosario de términos en mapudungun". La Araucania: El padre Sigifredo de Frauenhäusl y el Parlamento mapuche de Coz Coz de 1907. Eds. Carmen Arellano, Hermann Holzbauer y Roswitha Kramer. Madrid-Frankfurt: Vervuert. 431-471.

Catrileo, María. 2014. "El ngillatun como sistema conceptual mapuche". Estudios Filológi$\cos 53: 27-38$.

Claros, Edwing. 2011. "El Memorial de Charcas (1582)". Ciencia y Cultura 27: 26-62.

Cerrón-Palomino, Rodolfo. 2013. Las lenguas de los incas. Frankfurt: Peter Lang.

Cerrón-Palomino, Rodolfo y Enrique Ballón. 2011. Chipaya. Léxico-etnotaxonomía. Nijmegen: Radboud Universiteit. Lima: Fondo Editorial Universidad Católica del Perú.

Condori, Dionisio. 2016. Aymara kastilla ary pirwa / Diccionario aymara-castellano. Puno: Corporación Meru.

Cornejo, Luis. 2014. "Sobre la cronología del inicio de la imposición cuzqueña en Chile”. Estudios Atacameños 117: 101-116.

Cusihuaman, Antonio. 2001. Gramática quechua Cuzco-Collao. Cusco: Centro Bartolomé de Las Casas.

Delgado, Jorge y Mary Male. 2009. Despertar andino. Cusco: Taypi Qala Producciones.

Díaz-Fernández, Antonio. 1992. "Contacto del mapudungun con dos lenguas principales del Tawantinsuyu: el quechua y el yunga". Actas de la Lengua y la Literatura Mapuche 5: 193-201.

Dillehay, Tom. 2011. Monumentos, imperios y resistencia en los Andes. El sistema de gobierno mapuche y las narrativas rituales. San Pedro de Atacama: Universidad Católica del Norte.

Dillehay, Tom y Américo Gordon. 1998. "La actividad prehispánica de los incas y su influencia en la Araucanía”. La Frontera del Estado Inca. Comps. T. Dillehay y P. Netherly. Quito: Fundación Alexander von Humboldt y Editorial Abya-Yala. 183-196.

Dillehay, Tom, Mario Pino, Renée Bonzani, Claudia Silva, Johannes Wallner y Carlos Le Quesne. 2007. "Cultivated wetlands and emerging complexity in south-central Chile and long distance effects of climate change". Antiquity 81: 949-960.

Eco, Umberto, 1992. Los limites de la interpretación. Primera edición en castellano, Barcelona: Lumen.

Englert, Sebastián. 1934. "Los elementos derivados del aymará y el quichua en el idioma araucano". Anales de la Facultad de Filosofía y Educación. Santiago, Chile: Prensas de la Universidad de Chile. 1 (1): 5-27

Erize, Esteban. 1960. Diccionario comentado mapuche-español. Buenos Aires: Universidad Nacional del Sur.

Espinoza, Waldemar. 1987. Los incas: Economía, sociedad y estado en la era del Tahuantinsu- 
yo. Lima: Amaru Editores.

Febres, Andrés. 1765. Arte de la lengua general del reino de Chile. Lima: Calle de la Encarnación.

Fernández, María. 2015. Prendedores, topos y mujeres. La Paz: Museo Nacional de Etnografía y Folklore.

Garcilaso de la Vega, Inca. 2012 [1609]. Comentarios reales de los incas. Arequipa: Ediciones El Lector.

Golluscio, Lucía. 2009. "Loanwords in Mapudungun, a language of Chile and Argentina”. Loanwords in the world's languages: A comparative handbook. Eds. Martin Haspelmath y Uri Tadmor. Berlin: De Grouyer Monton. 1035-1071.

González de Holguín, Diego. 2007 [1608]. Vocabulario de la lengua general de todo el Perú llamada qquichua o del inca. Edición digitalizada por el Grupo Runasimipi Quespisqa Software. _http://www.letras.ufmg.br/padrao_cms/documentos/profs/romulo/ VocabvlarioQqichuaDeHolguin 1607.pdf 2 de Febrero 2019.

Gordon, Américo. 1978. "Urna y canoa funeraria. Una sepultura doble escavada en Padre Las Casas". Revista Chile de Antropologia 1: 61-80.

Grájeda, Eliseo. 2013. Diccionario enciclopédico qhiswha español. Cochabamba: Editorial Kilpus.

Greenberg, Joseph. 1987. Languages in the Americas. California: Stanford University Press.

Guamán Poma de Ayala, Felipe. 1980 [1615]. Nueva coronica y buen gobierno. Caracas: Biblioteca Ayacucho.

Guevara, Tomas. 1908. Psicolojía del pueblo araucano. Santiago: Imprenta Cervantes.

Haspelmath, Martin y Uri Tadmor. 2009. Loanwords in the world's languages: A comparative handbook. Berlin: De Gruyter Mouton.

Itier, Cesar. 2013. Viracocha o el océano. Lima: Instituto Francés de Estudios Andinos e Instituto de Estudios Peruano.

Jennings, Justings y Brenda Bowser, Eds. 2009. Drink, power, and society in the Andes. Gainesville: University Press of Florida.

Joseph, Claude. 1931. "La vivienda araucana". Anales de la Universidad de Chile 2: 229-251.

Kuramochi, Yosuke y Juan Nass. 1989. "Kamarikun: valoración de la tradición y causalidad". Actas de la Lengua y Literatura Mapuche 3: 25-56.

Kuramochi, Yosuke y Rosendo Huisca. 1997 Cultura mapuche: relatos, rituales y ceremonias. Quito: Abya-Yala.

Lafone, Samuel. 1898. Tesoro de catamequeñismos. Buenos Aires: Imprenta Pablo E. Eoni e Hijos.

Latcham, Ricardo, 1924. Organización social y creencias religiosas de los antiguos araucanos. Santiago: Imprenta Cervantes.

Lehmann-Nitsche, R., 1919. "El diluvio según los araucanos de la Pampa”. Revista del Museo de La Plata 24 (Segunda Serie): 28-62.

Lenz, Rodolfo. 1905-1910. Diccionario etimológico. Santiago: Universidad de Chile.

Lotman, Iuri. 1996. La semiósfera I. Semiótica de la cultura y el texto. Madrid: Ediciones 
Cátedra.

Lucca, Manuel de. 1983. Diccionario aymara-castellano, castellano-aymara. La Paz: Comisión de Alfabetización y Literatura Aymara.

Matienzo, Juan de. 1910 [1567]. Gobierno del Perú. Buenos Aires: Compañía Sudamericana de Billetes de Bancos.

Métraux, Alfred. 1946. "Ethnography of the Chaco". Handbook of the South American Indian. Ed. Julian Steward. Washington: Smithsonian Institution. 1: 197-380.

Middendorf, Ernst. 1890. Die inheimischen sprachen Perus: bd. worterbuch des runa simi üder der keshua-sprache. Leipzig: F.A. Brockhause.

Millones, Luis. 2010. Después de la muerte. Voces del limbo y del infierno en el territorio andino. Lima: Fondo Editorial del Congreso del Perú.

Monart, Gastón. 2005. Manual y glosario de la cultura y lengua mapuche pampa o mapudugun rankülche. Buenos Aires: Multimedios LA IDEA.

Mori, Juan de y Hernando de Soto. 1955-1956. La visitación de los pueblos de los indios [1549]. Paris / Lima: Instituto Francés de Estudios Andinos.

Moulian, Rodrigo. 2002. "Las trampas de la memoria: información, significación y sentido en la comunicación ritual. El caso del nguillatun huilliche”. Revista Austral de Ciencias Sociales 6: 47-68.

Moulian, Rodrigo. 2005. Tiempo de lepün: una etnografia visual del ngillatun williche. Valdivia: Universidad Austral de Chile y Programa Orígenes.

Moulian, Rodrigo. 2008. Ngen rüpu. El camino del ngen. Etnografía multimedia y arqueología de los simbolos. DVD. Valdivia: Consejo Nacional de la Cultura y de las Artes y Universidad Austral de Chile.

Moulian, Rodrigo. 2012. Metamorfosis ritual: desde el ngillatun al culto pentecostal. Valdivia: Editorial Kultrún y Universidad Austral de Chile.

Moulian, Rodrigo y María Catrileo. 2013. "Kamaska, kamarikun y müchulla: préstamos lingüísticos y encrucijadas de sentido en el espacio centro y sur andino". Alpha 37: 249-263.

Moulian, Rodrigo, María Catrileo y Pablo Landeo. 2015. "Afines quechua en el vocabulario mapuche de Luis de Valdivia". RLA: Revista de Lingüistica Teórica y Aplicada 53 (2): 73-96.

Moulian, Rodrigo, Felipe Hasler, María Catrileo y Jacqueline Caniguan. 2018. "Resonancias de la luz en las lenguas andinas: Un estudio de correlaciones en las constelaciones semióticas amerindias del brillo". Onomázein 42 [aceptado, en prensa].

Negro, Sandra. 1996. "La persistencia de la visión andina de la muerte en el virreinato del Perú”. Anthropologica 14: 121-141.

Oré, Jerónimo de. 1607. Ritvale sev Manvuale Pervanvm. Neapoli: Jacobum Carlinum et Constantinum Vitalem.

Ortiz de Zúñiga, Iñigo. 1967-1972 [1562]. Visita de la provincia de León de Huánuco en 1562. Ed. John Murra. Huánuco: Universidad Nacional Hermilio Valdizán. Facultad de Letras y Educación. 
Patrón, Pablo. 1912. "Influencia del dominio peruano en Chile". Trabajos del $4^{\circ}$ Congreso Cientifico, Sección Ciencias Naturales, Antropológicas y Etnológicas. Santiago, Chile: Imprenta Barcelona. Vol 17: 101-180.

Parker, Gary y Amancio Chávez. 1976. Diccionario Ancash-Huailas. Lima: Ministerio de Educación e Instituto de Estudios Peruanos.

Peirce, Charles Sanders. 1965. Collected Papers of Sanders Charles Peirce. Volume 2: Elements of Logic. Cambridge: The Belknap Press of Harvard University Press.

Petit, Lucrecia y Carolina Álvarez. 2014. “Pero que el camaruco no lo dejen de hacer, pase lo que pase'. Tensiones y (meta)reflexiones sobre las rogativas mapuche”. Corpus 4 (2). http://journals.openedition.org/corpusarchivos/1226. 26 de junio de 2018.

Pérez, Alberto y Georgina Erra. 2011. "Identificación de maíz en vasijas recuperadas de la Patagonia noroccidental argentina”. Magallania 39 (2): 309-316.

Ramos Gavilán, Alonso. 1976 [1621]. Historia de Nuestra Señora de Copacabana. La Paz: Cámara Nacional de Comercio.

Rosat, Adalberto. 2009. Diccionario enciclopédico quechua-castellano del mundo andino. Segunda edición. Cochabamba: Editorial Verbo Divino.

Rostworowski, María. 2005. "Redes económicas del Estado inca: el 'ruego' y la 'dádiva”. El Estado está de vuelta: desigualdad, diversidad y democracia. Ed. Víctor Vich. Lima: Instituto de Estudio Peruanos. 13-47.

Salomon, Frank. 1991. "Introductory essay: the Huarochiri manuscript". The Manuscript of Huarochiri. F. Salomon y Jorge Urioste. Austin: University of Texas Press. 1-38.

Sánchez, Gilberto. 2010. "Los mapuchismos en el DRAE”. El Boletín de Filología 65 (2): 149-156.

Saussure, Ferdinand. 1945. Curso de lingüística general. Buenos Aires: Losada.

Schindler, Helmut. 2006. "Continuidad y cambio en la liturgia mapuche: el kamarikun de la región de Coz Coz". La Araucania. El padre Sigifredo de Frauenhäusl y el Parlamento mapuche de Coz Coz de 1907. Eds. Carmen Arellano, Hermann Holzbauer y Roswitha Kramer. Madrid-Frankfurt: Vervuert. 73-97.

Tadmor, Uri. 2009. "Loanwords in the world's languages: Findings and results". Loanwords in the world's languages: A comparative handbook. Eds. Martin Haspelmath y Uri Tadmor. Berlin: De Gruyter Mouton. 55-75.

Titu Cusi Yupanqui, Diego de Castro. 1916 [1570]. Relación de los incas del Peru y hechos de Inca Manco II. Lima: Sanmartí y Cía.

Taylor, Gerald. 2000. Camac, camay y camasca y otros ensayos sobre Huarochiri y Yauyos. Lima: Centro de Estudios Regionales Andinos Bartolomé de Las Casas e Instituto Francés de Estudios Andinos.

Taylor, Gerald. 2001. Huarochiri: ritos y tradiciones. Lima: IFEA.

Torero, A. 1987. "Lenguas y pueblos altiplánicos en torno al siglo XVI". Revista Andina 10: 329-405.

Vaïsse, Emilio, Félix Hoyos y Aníbal Echevería. 1896. Glosario de la lengua atacameña. Santiago: Imprenta Cervantes. 
ESTUDIOS FILOLÓGICOS

Valda, María Luisa. 1964. Costumbres y curiosidades de los aymara. La Paz: Universo.

Valdivia, Luis de. 1887 [1606]. Arte y gramática general de la lengva que corre en todo el reyno de Chile con vn confessionario y vocabvlario. Ed. Julio Platzmann. Leipzig: B. G. Teubner.

van den Berg, Hans. 1985. Diccionario religioso aymara. Iquitos: Ceta-Idea.

Wilkox, Joan. 2004. Masters of the living energy: The mystical world of the Q'ero of Peru. Rochester: Inner Traditions. 